\title{
Removal of aqueous lead ions by hydroxyapatites: Equilibria and kinetic processes
}

\author{
Baillez Sandrine ${ }^{\mathrm{a}}$, Nzihou Ange ${ }^{\mathrm{a}, *}$, Bernache-Assolant Didier ${ }^{\mathrm{b}}$, \\ Champion Eric ${ }^{\mathrm{c}}$, Sharrock Patrick ${ }^{\mathrm{d}}$ \\ ${ }^{a}$ Laboratoire de Génie des Procédés des Solides Divisés, UMR 2392, Ecole des Mines d'Albi-Carmaux, \\ Campus Jarlard, Route de Teillet, 81013 Albi CT Cedex 09, France \\ ${ }^{\mathrm{b}}$ Ecole Nationale Supérieure des Mines de St Etienne, 158 cours Fauriel, 42023 St Etienne Cedex2, France \\ ${ }^{\mathrm{c}}$ SPCTS-Faculté des Sciences, Université de Limoges, 123 Ave. A. Thomas, 87060 Limoges Cedex, France \\ d LCBM, Université Paul Sabatier, Avenue Georges Pompidou, BP 258, 81104 Castres, France
}

\begin{abstract}
The capacity of hydroxyapatite (HAp) to remove lead from aqueous solution was investigated under different conditions, namely initial metal ion concentration and reaction time. The sorption of lead from solutions containing initial concentrations from 0 to $8000 \mathrm{mg} / \mathrm{L}$ was studied for three different $\mathrm{HAp}$ powders. Soluble $\mathrm{Pb}$ and $\mathrm{Ca}$ monitoring during the experiment allows characterizing the mechanism of lead uptake. Dissolution of calcium is followed by the formation of a solid solution, $\mathrm{Pb}_{x} \mathrm{Ca}_{10-x}\left(\mathrm{PO}_{4}\right)_{6}(\mathrm{OH})_{2}$, with a $\mathrm{Ca} / \mathrm{P}$ ratio decreasing continuously. Langmuir-Freundlich classical adsorption isotherms modeled adsorption data. The adsorption capacities calculated from this equation vary from $330 \mathrm{to} 450 \mathrm{mg} \mathrm{Pb} / \mathrm{g}$ HAp for the different solids. Modeling of the sorption process allows to determine theoretical saturation times and residual lead concentrations at equilibrium.
\end{abstract}

Keywords: Hydroxyapatite; Lead; Adsorption

\section{Introduction}

Calcium hydroxyapatite (HAp), $\mathrm{Ca}_{10}\left(\mathrm{PO}_{4}\right)_{6}(\mathrm{OH})_{2}$, is used for the removal of heavy metals from contaminated soils, wastewater and fly ashes [1-7]. Among heavy metals, lead was particularly studied with an aim to establish the mechanisms of lead capture by HAp. An ion exchange mechanism was proposed by Takeuchi et al. [8] in which lead ions are first adsorbed on the HAp surface and substitution with Ca occurs as described by the following equation:

$$
\begin{aligned}
& \mathrm{Ca}_{10}\left(\mathrm{PO}_{4}\right)_{6}(\mathrm{OH})_{2}+x \mathrm{~Pb}^{2+} \\
& \quad \rightarrow \mathrm{Ca}_{10-x} \mathrm{~Pb}_{x}\left(\mathrm{PO}_{4}\right)_{6}(\mathrm{OH})_{2}+x \mathrm{Ca}^{2+}
\end{aligned}
$$

The mass balance of lead is given by:

$$
m q=V\left(C_{0}-C\right)
$$

\footnotetext{
* Corresponding author.

E-mail address: ange.nzihou@enstimac.fr (N. Ange).
}

where $m$ is the weight of HAp (g), $q$ the amount of lead removed by unit of weight of HAp (mg Pb/g HAp), $V$ the volume of lead solution (l), $C_{0}$ the initial lead concentration of solution $(\mathrm{mg} \mathrm{Pb} / \mathrm{l})$ and $C$ is the concentration of lead at the time $t$ of adsorption ( $\mathrm{mg}$ $\mathrm{Pb} / \mathrm{l})$. After a long time, $C$ and $q$ will reach equilibrium value $C_{\mathrm{e}}$ and $q_{\mathrm{e}}$. As the exchange reaction between $\mathrm{Pb}^{2+}$ and $\mathrm{Ca}^{2+}$ described by Eq. (1) is very fast and seems to take place at the surface of HAp particles, the following rate equation can be given by

$$
\frac{\partial q}{\partial t}=K_{\mathrm{F}} a_{\mathrm{p}}\left(C-C_{\mathrm{s}}\right)
$$

where $K_{\mathrm{F}}$ is the Takeushi constant and $a_{\mathrm{p}}$ is the specific surface area of the particles. The initial conditions and equilibrium relation can be written as:

$$
\begin{aligned}
& C=C_{0} \quad \text { and } \quad q=0 \quad \text { at } t=0, \quad \text { and } q_{\mathrm{e}}=\text { constant } \\
& q=\left(\frac{q_{\mathrm{e}}}{C_{\mathrm{e}}}\right) C_{\mathrm{s}}
\end{aligned}
$$


The interaction of HAp with heavy metals may form relatively insoluble metal phosphates and/or result in the sorption of heavy metal on HAp, thus significantly reducing aqueous metal concentrations. The study of the equilibrium will help to determine the adsorption capacity of the hydroxyapatite powders used. This capacity is an important parameter to design a pilot plant which could be used for wastewater treatment.

Adsorption isotherms are used to determine the affinity of HAp for lead. The lead concentration at equilibrium $\left(C_{\mathrm{e}}\right)$ helps to calculate the amount of lead $\left(q_{\mathrm{e}}\right)$ removed by unit weight of HAp at the end of the experiment. This quantity is defined as follows:

$q_{\mathrm{e}}=\frac{\left(C_{0}-C_{\mathrm{e}}\right) V}{m}$

An isotherm model such as the Freundlich-Langmuir model is generally used to describe the sorption of heavy metals by natural adsorbents [9-12]

$q_{\mathrm{e}}=Q_{0} \frac{k_{\mathrm{FL}} C_{\mathrm{e}}^{1 / n_{\mathrm{FL}}}}{1+k_{\mathrm{FL}} C_{\mathrm{e}}^{1 / n_{\mathrm{FL}}}}$

where $Q_{0}$ is lead concentration on solid surface in equilibrium with the initial liquid concentration ( $\mathrm{mg} \mathrm{Pb} \mathrm{Pb}^{2+} / \mathrm{g} \mathrm{HAp}$ ), $k_{\mathrm{FL}}$ is related to the kinetics of adsorption $\left(\mathrm{mg} \mathrm{Pb}^{2+} / \mathrm{g} \mathrm{HAp}\right)$ and $C_{\mathrm{e}}$ is the equilibrium concentration of lead $(\mathrm{mg} / \mathrm{l})$.

\section{Materials and methods}

Two series of experimental measurements were carried out: (1) batch sorption measurements to determine kinetic parameters and the effect of $\mathrm{pH}$ on lead removal and (2) adsorption measurements to define the adsorption efficiency of HAp for lead. All experiments were carried out with three different HAps synthesized at room temperature by precipitation from solution [13]. The solids obtained were dried at $105^{\circ} \mathrm{C}$ during 1 day and ground to obtain monomodal powders.

$\mathrm{X}$-ray powder diffraction measurements (XRD), were carried out with $\mathrm{Cu} \mathrm{K} \alpha$ radiation from 20 to $50^{\circ}$ (Siemens D5000). The phases present were determined by comparing the patterns with JCPDS standards. The XRD pattern of powder calcined at $1000{ }^{\circ} \mathrm{C}$ during $15 \mathrm{~h}$ shows that $\mathrm{HAp}_{1}$ is composed of hydroxyaptite and tricalcium phosphate (TCP) with a $\mathrm{Ca} / \mathrm{P}$ ratio of 1.6004. $\mathrm{HAp}_{2}$ is a stoichiometric HAp, $\mathrm{Ca}_{10}\left(\mathrm{PO}_{4}\right)_{6}(\mathrm{OH})_{2}$ with a $\mathrm{Ca} / \mathrm{P}$ ratio of $1.6669 . \mathrm{HAp}_{3}$ is composed of hydroxyapatite and lime $(\mathrm{CaO})$ with a $\mathrm{Ca} / \mathrm{P}$ ratio of 1.7275 . The specific surface area of the particles was determined by nitrogen adsorption using a BET method (MICROMERITICS Gemini Vacprep 061). The bulk density of the powder was measured by helium pycnometry (MICROMERITICS Accupyc 1330). The powder particles size distribution was determined with a MALVERN Laser Mastersizer Hydro 2000. The particles were placed in an ethanol suspension shaken by ultrasound. This characterization of the three HAp powders gave the following results (Table 1).

Aqueous solutions containing $\mathrm{Pb}^{2+}$ ions of concentration $(1000,2000,3000,5000,6000$ and $8000 \mathrm{mg} / \mathrm{l})$ were prepared from lead nitrate. The initial $\mathrm{pH}$ of the suspension varied from 3 to 5 depending on the concentration of lead in the solution.
Table 1

Hydroxyapatite properties

\begin{tabular}{lccc}
\hline & $\mathrm{HAp}_{1}$ & $\mathrm{HAp}_{1}$ & $\mathrm{HAp}_{1}$ \\
\hline $\mathrm{Ca} / \mathrm{P}$ molar ratio & 1.60 & 1.67 & 1.73 \\
Specific surface area $\left(\mathrm{m}^{2} / \mathrm{g}\right)$ & 41 & 50 & 104 \\
Bulk density $\left(\mathrm{g} / \mathrm{cm}^{3}\right)$ & 2.97 & 2.92 & 2.80 \\
$d(50)(\mu \mathrm{m})$ & 11 & 16 & 18 \\
\hline
\end{tabular}

Four grams of HAp were introduced in a stirred-tank reactor containing $400 \mathrm{ml}$ of the prepared solution after $10 \mathrm{~min}$ of equilibration time. The stirring speed of the agitator was $400 \mathrm{rpm}$. The temperature of the suspension was maintained at $25^{\circ} \mathrm{C}$.

The lead and calcium concentrations in the solution during the run were determined by an atomic absorption photometer (VARIAN Spectra AA 400). After $24 \mathrm{~h}$ of reaction, the sample was filtered and dried at $105^{\circ} \mathrm{C}$ during $2 \mathrm{~h}$.

\section{Results and discussion}

The evolution of lead concentrations during the batch sorption experiment for $\mathrm{HAp}_{2}$ is presented in Fig. 1. The curves show a swift decrease of lead concentration during the first minutes. The final concentration corresponds to the equilibrium or to the entire consumption of lead.

Both the $\mathrm{Pb}^{2+}$ concentration evolutions and the $\mathrm{pH}$ decreases observed in Figs. 1 and 2 for the first few minutes can be explained by surface complexation. In fact, Mavropoulos et al.

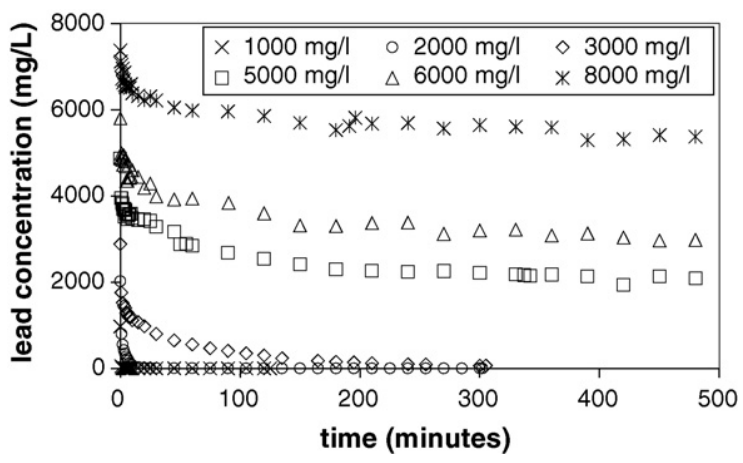

Fig. 1. Batch sorption kinetic measurements for $\mathrm{HAp}_{2}$.

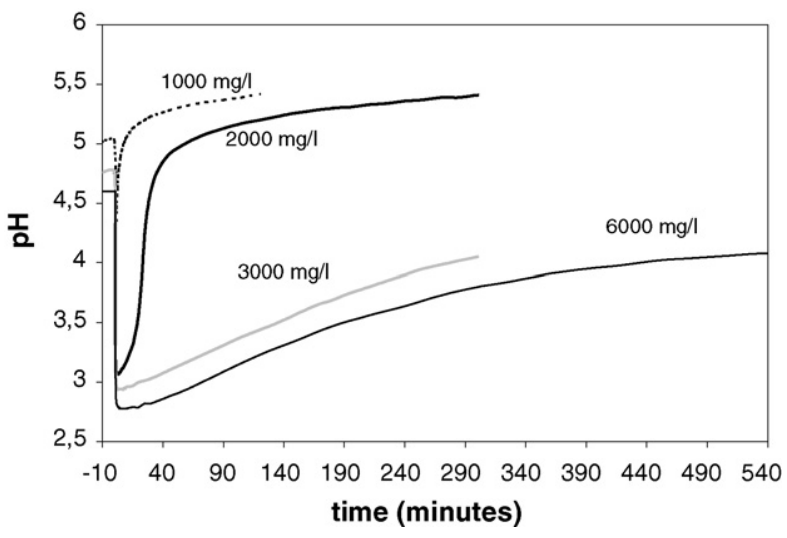

Fig. 2. Effect of $\mathrm{Pb}$ sorption on the $\mathrm{pH}$ of the solution for $\mathrm{HAp}_{2}$. 


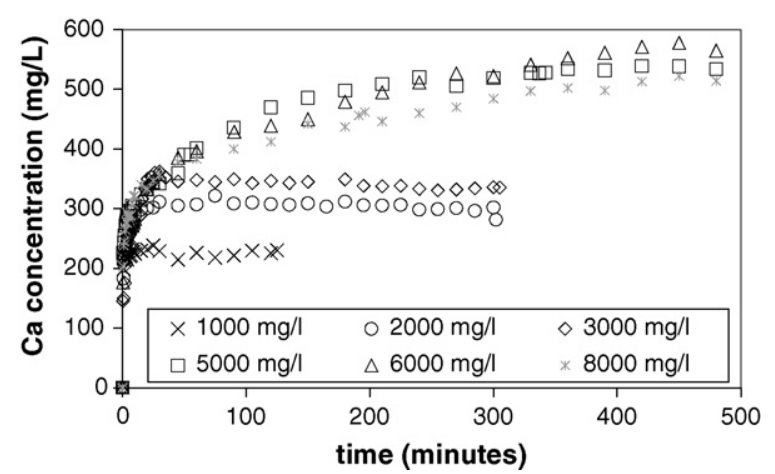

Fig. 3. $\mathrm{Ca}^{2+}$ released into the solution for $\mathrm{HAp}_{2}$.

[5] postulated that surface $\equiv \mathrm{POH}$ sites of hydroxylapatite in neutral water are transformed into $\equiv \mathrm{POPb}^{+}$sites, which leads to proton leaching and consequently explains the initial $\mathrm{pH}$ decrease and calcium dissolution observed in Fig. 3. The progressive return towards initial $\mathrm{pH}$ values depends on the initial lead concentration, with higher concentrations responding more slowly.

Fig. 4 establishes the relation between $\mathrm{Pb}^{2+}$ uptake and $\mathrm{Ca}^{2+}$ release. The slope of this curve is approximately equal to unity suggesting that the reaction mechanism corresponds to equimolar exchange of lead and calcium yielding $\mathrm{Ca}_{10-x} \mathrm{~Pb}_{x}\left(\mathrm{PO}_{4}\right)_{6}(\mathrm{OH})_{2}$, where $x$ can vary from 0 to 10 depending on the reaction time and experimental conditions. Similar results were obtained with $\mathrm{HAp}_{1}$ and $\mathrm{HAp}_{3}$. The proposed mechanism for lead removal by Hap comprises two steps: firstly, rapid surface complexation of the lead on the $\equiv \mathrm{POH}$ sites of the HAp which causes the decrease of the $\mathrm{pH}$ and secondly, partial dissolution of calcium followed by the precipitation of an apatite with formula: $\mathrm{Pb}_{x} \mathrm{Ca}_{10-x}\left(\mathrm{PO}_{4}\right)_{6}(\mathrm{OH})_{2}$. Fig. 5 shows the adsorption isotherms for the three HAps. For $C_{\mathrm{e}}$ above $500 \mathrm{mg} / \mathrm{l}$, the amount of sorbed lead, $q_{\mathrm{e}}$, does not increase significantly. This plateau corresponds to the saturation of the HAp surface which can be modeled with the Langmuir-Freundlich Eq. (7). Table 2 lists the values of the resulting parameters.

The results confirm the large affinity of lead for all the HAps studied. $\mathrm{HAp}_{1}$ and $\mathrm{HAp}_{2}$ have same specific surface areas, but $\mathrm{HAp}_{1}$ has the higher adsorption capacity. As $\mathrm{HAp}_{1}$ is a deficient HAp $(\mathrm{Ca} / \mathrm{P}<1.67)$, the cation deficiency can be compensated by lead ions in order to obtain a stoichiometric apatite

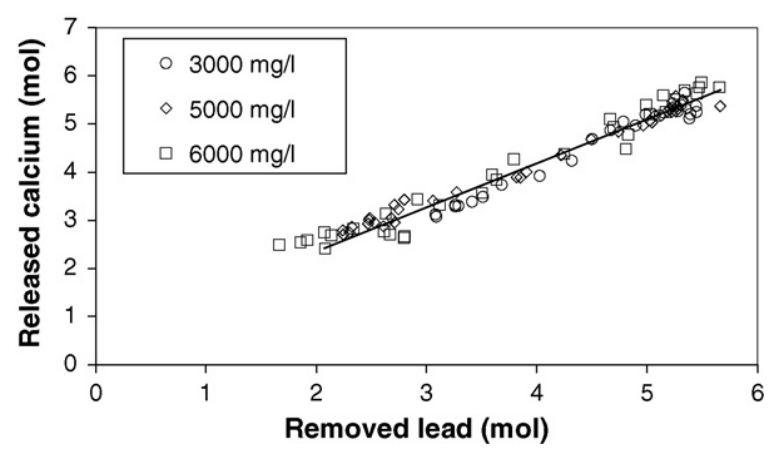

Fig. 4. Moles of $\mathrm{Ca}^{2+}$ released into the solution as function of moles of $\mathrm{Pb}^{2+}$ removed from the solution.

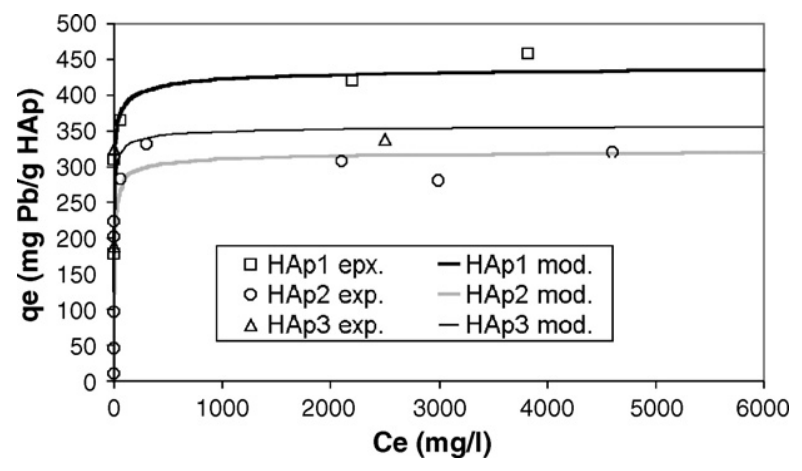

Fig. 5. Adsorption isotherms for the three hydroxyapatites.

Table 2

Langmuir-Freundlich parameters

\begin{tabular}{lccr}
\hline & $\mathrm{HAp}_{1}$ & $\mathrm{HAp}_{2}$ & $\mathrm{HAp}_{3}$ \\
\hline$n_{\mathrm{LF}}(\mathrm{mg} \mathrm{Pb} / 1)^{\left.-1 / n_{\mathrm{LF}}\right]}$ & 2.6 & 2.5 & 2 \\
$k_{\mathrm{LF}}[(\mathrm{mg} \mathrm{Pb} / 1)$ & 1 & 1 & 1 \\
$q_{\max }(\mathrm{mg}$ & 330 & 360 \\
\hline
\end{tabular}

(i.e. $(\mathrm{Ca}+\mathrm{Pb}) / \mathrm{P}=1.67)$. The calculated theoretical formulas of the solid phosphates formed have the molar ratios presented in Table 3.

The $\mathrm{Ca} / \mathrm{P}$ molar ratios of the HAps at the end of the experiments are higher than 1.67. Based on the experimental concentration-decay curves, the mass balance was solved using a Runge-Kutta Telhberg equation [14], assuming diffusion in the macropores is rate determining and that the equilibrium relationship is given by Langmuir-Freundlich isotherms at any specified radial position. If the hydroxyapatite particles are spherical and their dimension and porosity are uniform, the differential mass balance on a spherical shell element is:

$\frac{1}{r} \frac{\partial}{\partial r}\left(r^{2} D_{\mathrm{ef}} \frac{\partial C}{\partial r}\right)=\frac{\partial C}{\partial t}+\left(\frac{1-\varepsilon_{\mathrm{p}}}{\rho}\right) \frac{\partial q}{\partial t}$

The tortuosity, $\tau$ of the adsorbent was taken equal to 4 referring to other natural adsorbent tortuosities varying from 2 to 6 [9]. The macropore diffusivity was taken as independent of concentration, with $\varepsilon_{\mathrm{p}}$ is the porosity of the HAp particles (0.49), $q$ the adsorbate quantity per gram of HAp and $D_{\text {ef }}$ is the effective diffusivity, related to the molecular diffusivity $D_{\mathrm{M}}$ by the relation:

$D_{\mathrm{ef}}=\frac{\varepsilon_{\mathrm{p}}}{\tau} D_{\mathrm{M}}$

Assigning a value of $D_{\mathrm{M}}=2.6 \times 10^{-7} \mathrm{~m} / \mathrm{s}$, the effective diffusivity $D_{\text {ef }}$ of lead in the liquid phase inside micropores is then

Table 3

Hydroxyapatite formula before and after lead removal

\begin{tabular}{llllll}
\hline & At the beginning & & & At the end \\
\cline { 2 - 3 } \cline { 5 - 6 } & Formula & $\mathrm{Ca} / \mathrm{P}$ & & Formula & $(\mathrm{Ca}+\mathrm{Pb}) / \mathrm{P}$ \\
\hline $\mathrm{HAp}_{1}$ & $\mathrm{Ca}_{9.6}\left(\mathrm{PO}_{4}\right)_{6}(\mathrm{OH})_{2}$ & 1.6 & & $\mathrm{~Pb}_{2.13} \mathrm{Ca}_{8.12}\left(\mathrm{PO}_{4}\right)_{6}(\mathrm{OH})_{2}$ & 1.71 \\
$\mathrm{HAp}_{2}$ & $\mathrm{Ca}_{10}\left(\mathrm{PO}_{4}\right)_{6}(\mathrm{OH})_{2}$ & 1.67 & & $\mathrm{~Pb}_{1.5} \mathrm{Ca}_{9}\left(\mathrm{PO}_{4}\right)_{6}(\mathrm{OH})_{2}$ & 1.75 \\
$\mathrm{HAp}_{3}$ & $\mathrm{Ca}_{10.38}\left(\mathrm{PO}_{4}\right)_{6}(\mathrm{OH})_{2}$ & 1.73 & & $\mathrm{~Pb}_{1.71} \mathrm{Ca}_{8.59}\left(\mathrm{PO}_{4}\right)_{6}(\mathrm{OH})_{2}$ & 1.72
\end{tabular}


Table 4

Comparison between experimental and model results

\begin{tabular}{lcccc}
\hline$C_{0, \exp }\left(\mathrm{g} \mathrm{Pb} / \mathrm{M}^{3}\right)$ & $C_{\mathrm{e}, \exp }\left(\mathrm{g} \mathrm{Pb} / \mathrm{M}^{3}\right)$ & $t_{\mathrm{c}, \exp }(\mathrm{s})$ & $C_{\mathrm{e}}\left(\mathrm{g} \mathrm{Pb} / \mathrm{M}^{3}\right)$ & $t_{\mathrm{c}}(\mathrm{s})$ \\
\hline 2000 & 0 & 1.5 & 0 & 1.3 \\
5000 & 2000 & 5 & 8 & 2400 \\
6000 & 3200 & 11.5 & 30 & 28000 \\
\hline
\end{tabular}

$3.1 \times 10^{-8} \mathrm{~m} / \mathrm{s}$. Using normal initial and boundary conditions, the characteristic time $t_{\mathrm{c}}$ corresponding to the time required for the saturation of the hydroxyapatite is then deduced as:

$t_{\mathrm{c}}=\frac{\left(1-\varepsilon_{\mathrm{p}}\right) C_{\mathrm{e}} r_{\mathrm{p}}^{2}}{D_{\mathrm{ef}} C_{0}}$

Based on the experimental concentration-decay curves such as those shown in Fig. 1, the mass balance was solved for our experimental conditions and yielded the theoretical saturation times $t_{\mathrm{c}}$ and equilibrium concentrations $C_{\mathrm{e}}$. The comparison between the experimental and model results is summarized in Table 4. We observe that adsorption takes a very long time before attaining saturation with extremely low values of residual lead concentrations in water. The results show that even after a few hours, when the adsorption kinetics become very slow, the sorption capacity remains very high.

Modeling of the reaction kinetics shows that after $24 \mathrm{~h}$ (time limit of our experiments) the reaction is not finished but is in fact very slow. So, with longer contact times, higher sorption capacity could be obtained.

\section{Conclusions}

Isothermal batch adsorption results show that hydroxyapatite is able to remove important quantities of lead (between 330 and $450 \mathrm{mg} \mathrm{Pb} / \mathrm{g}$ HAp for the three studied hydroxyapatites). Experimental and theoretical considerations show that a high specific surface area and a large porosity are favorable parameters for lead adsorption. The kinetic results show that the lead uptake by hydroxyapatite proceeds with a rapid surface complexation of the lead on the $\equiv \mathrm{POH}$ site before the formation of a pyromorphite compound of formula $\mathrm{Ca}_{10-x} \mathrm{~Pb}_{x}\left(\mathrm{PO}_{4}\right)_{6}(\mathrm{OH})_{2}$. The model results predict that hydroxylapatite may be an effective sorbent to remove dilute lead from aqueous solutions for long time periods before reaching saturation. The phase purity or $\mathrm{Ca} / \mathrm{P}$ ratio of the adsorbent is not of critical importance for the material's capacity. This leads to interesting prospects for the use of hydroxylapatites in water purification.

\section{Acknowledgement}

The authors would like to thank the European Commission under the Asia Link Programme (Number: CN/ASIA-LINK/010 (94-556)) for providing support to this work.

\section{References}

[1] X. Chen, J.V. Wright, J.L. Conca, L.M. Peurrung, Effects of pH on heavy metal sorption on mineral apatite, Environ. Sci. Technol. 31 (3) (1997) 624-631.

[2] V. Laperche, S.J. Traina, P. Gaddam, T.J. Logan, J.A. Ryan, Chemical and mineralogical characterizations of $\mathrm{Pb}$ in a contaminated soil: reactions with synthetic apatite, Environ. Sci. Technol. 30 (1996) 33213326.

[3] Q.Y. Ma, S.J. Traina, T.J. Logan, J.A. Ryan, In situ lead immobilization by apatite, Environ. Sci. Technol. 27 (1993) 1803-1810.

[4] Q.Y. Ma, S.J. Traina, T.J. Logan, J.A. Ryan, Effects of Aqueous Al, Cd, $\mathrm{Cu}, \mathrm{Fe}(\mathrm{II}), \mathrm{Ni}$, and $\mathrm{Zn}$ on $\mathrm{Pb}$ immobilization by hydroxyapatite, Environ. Sci. Technol. 28 (1994) 1219-1228.

[5] E. Mavropoulos, A.M. Rossi, A.M. Costa, C.A. Perez, J.C. Moreira, M. Saldanha, Studies on the mechanisms of lead immobilization by hydroxyapatite, Environ. Sci. Technol. 36 (2002) 1625-1629.

[6] A. Nzihou, P. Sharrock, Calcium phosphate stabilization of fly ash with chloride extraction, Waste Manag. 22 (2002) 235-239.

[7] Y. Takeuchi, H. Arai, Removal of coexisting $\mathrm{Pb}^{2+}, \mathrm{Cu}^{2+}, \mathrm{Cd}^{2+}$ ions from water by addition of hydroxyapatite powder, J. Chem. Eng. Jpn. 23 (1990) 75-80.

[8] Y. Takeuchi, T. Suzuki, H. Arai, A study of equilibrium and mass transfer in processes for removal of heavy metal ions by hydroxyapatites, J. Chem. Eng. Jpn. 21 (1) (1998) 98-100.

[9] D.M. Ruthven, Principles of Adsorption and Adsorption Processes, John Wiley \& Sons, New York, 1984, p. 433.

[10] S. Rengaraj, K.-H. Yeon, S.-H. Moon, Removal of chromium from water and wastewater by ion exchange resins, J. Hazard. Mater. B87 (2001) 273-287.

[11] S. Rengaraj, K.-H. Yeon, S.-Y. Kang, J.-U. Lee, K.-W. Kim, S.-H. Moon, Studies on adsorptive removal of $\mathrm{Co}(\mathrm{II}), \mathrm{Cr}(\mathrm{III})$ and Ni(II) by IRN77 cationexchange resin, J. Hazard. Mater. B92 (2002) 185-198.

[12] S. Rengaraj, S.H. Moon, Kinetics of adsorption of Co(II) removal from water and wastewater by ion exchange resins, Water Res. 36 (2002) 1783-1793.

[13] S. Bailliez, Adsorption du plomb sur des hydroxyapatites et frittage thermique: processus cinétiques et transfert thermique. Thesis of INSA de LYON, 2003

[14] R.B. Bird, W.E. Stewart, E.N. Lightfoot, Transport Phenomena, John Wiley \& Sons, New York, 1960, p. 780 